\title{
Erratum: 'Succession of one-soliton pulses in the zero-dispersion region of silica optical fibres: the role of the phase difference between adjacent pulses'
}

I. M. UZUNOV and V. M. MITEV, Optical and Quantum Electronics 21, (1989) 507.

Figure $1 \mathrm{a}$ is erroneous. The correct dynamics for the same conditions as in Fig. 1a are shown in Fig. 1, below.

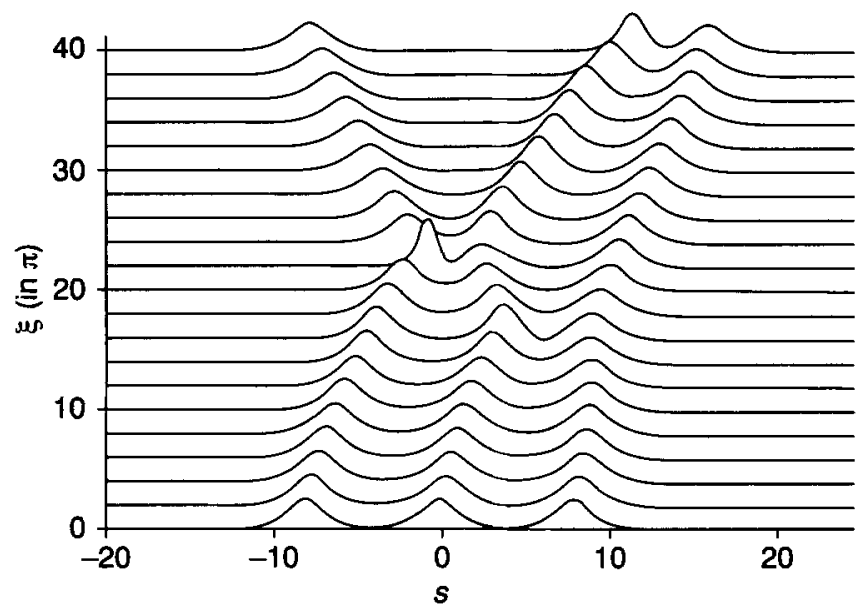

Figure 1 